\title{
Pharmacotherapy of Alcohol and Drug Dependence
}

\author{
Robert M. Swift • Elie G. Aoun
}

Published online: 14 November 2014

(C) Springer International Publishing AG 2014

\begin{abstract}
Advances in neurobiology have increased our understanding of the underlying mechanisms of drug and alcohol dependence and led to the development of medications to treat addictive disorders (Koob GF, Volkow ND. Neurocircuitry of addiction. Neuropsychopharmacology.2010;35(1):217-38). Addictive disorders are increasingly recognized as medical conditions, influenced by genetic, biological and psychosocial factors, for which the optimal treatment combines both pharmacological and psychosocial therapies (McLellan AT,Lewis DC, O'Brien CP, Kleber HD. Drug dependence, a chronic medical illness: implications for treatment, insurance, and outcomes evaluation. JAMA.2000;284(13):1689-95). This review discusses the neurobiology and physiology of addiction, the putative mechanisms of action of pharmacotherapies in the treatment of addictive disorders and the evidence for their efficacy.
\end{abstract}

Keywords Addictions · Substance use disorders · Alcohol · Opioids

\section{Introduction: The Neurobiology of Drug and Alcohol Dependence}

Drug use, alcohol use and compulsive behavior disorders such as gambling share common neurochemical substrates that

This article is part of the Topical Collection on Addictions

R. M. Swift

From the Center for Alcohol and Addiction Studies, Brown

University Alpert School of Medicine, Providence, RI, USA

R. M. Swift • E. G. Aoun

Department of Psychiatry and Human Behavior, Brown University

Alpert School of Medicine, Providence, RI, USA

R. M. Swift $(\bowtie)$

ACOS For Research, VA Medical Center, 830 Chalkstone Avenue, Providence, RI 02908, USA

e-mail: Robert_Swift_MD@brown.edu produce rewarding responses, distress relief and long-term neuroadaptations, which lead to addiction [1-3]. Neuroadaptation is mediated initially through enhanced brain reward mechanisms $[4,5]$ and later through the avoidance of withdrawal and development of allostasis [6]. Susceptibility to addictive disorders stems from genetic and environmental factors and from gene-environment interactions.

Drug reward is associated with the brain's motivational system through activation of the mesolimbic dopamine pathway and related limbic structures including the amygdala, hippocampus and medial prefrontal cortex, which regulate responses to natural reinforcers, such as food, sex and social interaction [7]. Drug-induced dopamine release into the nucleus accumbens, amygdala and prefrontal cortex is associated with reward and an increased salience for the stimulus. Repeated activation of this motivation-reward system sensitizes the system, leading to craving and compulsive use [8]. Drugs activate the mesolimbic pathway directly (cocaine and stimulants) or indirectly (nicotine, cannabinoids opioids and alcohol). Compulsive behaviors such as gambling may increase dopamine release by stimulating endogenous opioid pathways innervating the ventral tegmental area and the nucleus accumbens.

Adaptive brain changes following chronic use require the constant presence of the addictive substance or behavior to maintain homeostasis [9]. Withdrawal of the substance leads to an acute, intense, typically physically and emotionally unpleasant reaction. For example, withdrawal from sedatives and alcohol can cause anxiety, labile mood, seizures and death. The duration and intensity of symptoms depend on the pharmacokinetics and pharmacodynamics of the drug, the amount and duration of use, and individual differences in vulnerability to withdrawal. Avoidance of withdrawal becomes an important factor in maintaining substance use.

After acute withdrawal symptoms have abated, abstinent individuals typically experience a protracted, distressing state characterized by anxiety, dysphoria and difficulty coping with 
stress. Reward deficiency due to a reduction in dopamine response to reinforcing stimuli [10] and from activation of the brain's stress response system creates abnormalities in central corticotrophin-releasing factor (CRF), neuropeptide Y (NPY), norepinephrine and other stress response neurotransmitters [11]. Rapid relief of stress by the addictive substance makes stressful situations a powerful precipitant of relapse [12, 13]. Long-term substance use is also associated with craving, defined as a strong conscious urge or desire to use the substance. When craving is strong, drug use becomes a preoccupation difficult to resist. External cues, such as exposure to sights, sounds or smells associated with drug use, and internal cues, such as anger or sadness, can elicit craving for alcohol or drugs after prolonged periods of abstinence. Drug and alcohol craving is associated with increased risk of relapse, particularly early in the post-treatment period [14]. Long-term neuroplasticity and learning in the dorsolateral striatum and other cortico-basal ganglia circuits also result in automatic or habitual use that can be unconscious and not related to reward or relief $[15,16]$.

\section{Mechanisms of Action of Pharmacotherapies}

The treatment of addictions involves promoting the avoidance of psychoactive substances, developing coping skills, and improving self-esteem and self-efficacy. Pharmacotherapies can act through several mechanisms to reduce the impetus for drug use (Table 1). Important targets for medications include reducing the positively reinforcing stimulant effects of alcohol and drugs [5]; increasing the aversive effects of the substance by producing nausea, anxiety or dysphoria; and

Table 1 Actions of medications used for addiction treatment

1. Medications with similar properties that can partially substitute for the abused substance

Examples: methadone or buprenorphine substitution (opioid dependence); gamma-hydroxybutyrate (GHB) (alcohol dependence)

2. Medications that block the positive reinforcing and stimulating effects of the substance

Example: naltrexone (opioid dependence; alcohol dependence)

3. Medications that relieve the distress of withdrawal and allostasis

Example: topiramate (alcohol dependence), varenicline (nicotine dependence),

4. Medications that produce aversive effects when the substance is used Example: disulfiram (alcohol dependence)

5. Medications that reduce craving

Example: naltrexone (alcohol dependence)

6. Medications that treat comorbid psychiatric disorders

Example: antidepressants (comorbid depression and alcohol dependence) reducing the symptoms of abstinence and withdrawal, thereby reducing craving and the tendency to relapse.

Another potential target for medications to treat addictions is management of the symptoms of comorbid psychiatric disorders and psychosocial distress, thus reducing the need to self medicate. Alcohol and drug dependence frequently cooccurs with psychiatric disorders, especially schizophrenia, bipolar disorder, panic disorder and post-traumatic stress disorder [17]. The following sections discuss the use of pharmacotherapy to treat alcohol, cannabis, nicotine, opioid and stimulant dependence, as well as the behavioral addiction, pathological gambling.

Medications to Treat Alcohol Dependence

\section{Disulfiram Aversive Therapy}

Disulfiram inhibits the enzyme acetaldehyde dehydrogenase, causing acetaldehyde, a toxic alcohol metabolite, to accumulate after alcohol is consumed, resulting in aversive symptoms such as skin flushing, tachycardia, sweating, shortness of breath, nausea and vomiting. As such, a disulfiram reaction provides a strong deterrent to alcohol consumption. [18]. Indeed, natural polymorphisms of genes encoding alcoholmetabolizing enzymes that result in acetaldehyde accumulation are also associated with reduced drinking [19, 20].

Although disulfiram has been used since the 1950s, there have been few well-controlled studies on its effectiveness. A large, multicenter double-blind, randomized controlled trial (RCT) conducted in 605 alcohol-dependent veterans found disulfiram to be no more effective than placebo in promoting alcohol abstinence [21]. In a 12-week RCT of 122 patients with combined cocaine and alcohol dependence receiving a manualized psychotherapy and either disulfiram or no medication, those receiving disulfiram had better treatment retention and longer duration of abstinence from both cocaine and alcohol use [22].

More recent studies suggest that direct supervision of disulfiram ingestion increases its effectiveness [23]. In a 6month RCT involving 126 patients who took $200 \mathrm{mg}$ disulfiram or $100 \mathrm{mg}$ vitamin $\mathrm{C}$ under supervision, disulfiramtreated patients had more abstinent days, reduced drinking and lower gamma-glutamyl transpeptidase levels [18]. In couples receiving behavioral marital therapy, those with a contract for spousal supervision of disulfiram compliance had less drinking than couples without supervision [24].

The usual disulfiram dose is $250 \mathrm{mg}$ daily (range 125$500 \mathrm{mg}$ ). When large amounts of alcohol are consumed concurrent with disulfiram, cardiac problems, hypotension and death may occur [18]. Disulfiram can also produce hepatotoxicity. In spite of its potential toxicity and questions about its effectiveness, disulfiram can be a useful adjunct to treatment for some patients. 


\section{Opioid Antagonists - Naltrexone and Nalmefene}

After animal studies showed that opioid antagonists were associated with a reduction in alcohol consumption, two 12week RCTs in alcohol-dependent patients demonstrated that naltrexone reduced heavy drinking and prolonged abstinence $[25,26]$. Based on these studies, in 1994, the US Food and Drug Administration (FDA) approved naltrexone as an adjunct to psychosocial therapies in the treatment of alcoholism. Several meta-analyses of naltrexone clinical trials demonstrate consistent effectiveness with modest effect sizes for efficacy (0.15-0.2) in reducing heavy drinking [27-29]. Naltrexone does not consistently promote abstinence [30]. There is evidence of greater effectiveness in individuals who carry the Asp40 (118G) allele of OPRM1, which encodes the muopioid receptor $[31,32]$.

At the usual daily dosage of naltrexone (i.e., $50 \mathrm{mg}$ ), approximately $10 \%$ of patients experience anxiety, sedation and/or nausea. Hepatotoxicity has been reported at higher, 300-mg daily doses [33]. Patients taking naltrexone are insensitive to opioid effects, including analgesia, although the effect dissipates within $72 \mathrm{~h}$ of drug discontinuation. If opioid analgesics are needed emergently, the blockade can be reversed with carefully monitored high-dose opioids. A Treatment Improvement Protocol (TIPS) published by the Substance Abuse Mental Health Services Administration (SAMHSA) provides comprehensive information and treatment guidelines for naltrexone [34]. To address poor medication adherence with oral naltrexone, a sustained-release, intramuscular naltrexone preparation is FDA approved for the treatment of alcohol dependence via a once monthly injection [35].

Nalmefene is an opioid antagonist initially approved for the reversal of opioid intoxication. It differs from naltrexone in having partial agonist activity at the kappa-opioid receptor and less hepatotoxicity. Mason and colleagues conducted an RCT in 21 alcohol-dependent [36] and a follow-up RCT in 105 alcohol-dependent participants [37]. Both studies showed the superiority of nalmefene, combined with psychosocial treatment in reducing heavy drinking. In contrast, a multisite, 12-week RCT in which 270 abstinent alcohol-dependent participants received placebo or nalmefene, along with motivational enhancement therapy, showed no efficacy for nalmefene [38]. Two recent European RCTs in which alcohol-dependent subjects were randomized to receive nalmefene or placebo in a targeted or "as needed fashion" (i.e., on days when participants perceived that they were at high risk for drinking) showed efficacy in reducing the number of drinking days and total amount of alcohol consumed [39, 40]. Nalmefene is approved for alcoholism treatment in the European Union, although not currently in the USA.

\section{Acamprosate}

Acamprosate, a structural analog of the brain chemical taurine, reduces alcohol consumption in animal models. It also reduced withdrawal distress and craving [41]. Its mechanism of action is not completely understood but involves a modulation of the n-methyl-d-aspartate (NMDA) glutamate receptor, which is upregulated in chronic alcoholism. Multiple RCTs, mostly conducted in Europe, showed that acamprosate added to psychosocial intervention improves the duration and rate of abstinence [42]. Three European multicenter RCTs supported the FDA approval of acamprosate as an effective agent in the maintenance of abstinence from alcohol [43-45]. Two meta-analyses across several studies show a small effect of acamprosate in improving the rate of abstinence and increasing the time to first drink [28, 46].

Two US trials, a 6-month multisite study [47] and the COMBINE Study [48], and a recent multisite German trial [49] failed to find similar efficacy. The reasons for the differences in effectiveness are unclear, but it has been suggested that differences in the severity of alcoholism, patient characteristics and the use of inpatient detoxification in early studies may explain the divergent results.

\section{Sedatives and Anticonvulsants}

Although benzodiazepines (e.g., diazepam, chlordiazepoxide) are commonly used medications for alcohol detoxification, most addiction professionals oppose their use for relapse prevention because of the risk of dependence. Recently, several European studies have suggested that the sedative gamma-hydroxybutyrate (GHB) may be useful for the treatment of alcohol dependence. However, its use is limited by its abuse potential [50].

Antiepileptics such as carbamazepine, topiramate, valproic acid and gabapentin have been used successfully to treat alcohol withdrawal [51] and are reported to reduce consumption in dependent subjects. In a 12-week RCT in 150 patients, topiramate significantly decreased the numbers of drinks per day, drinks per drinking day and drinking days, and it increased the number of days of abstinence compared to placebo [52]. A subsequent US multisite trial [53] also showed topiramate to be efficacious in reducing heavy drinking, while another RCT showed a reduction in heavy drinking days and increased abstinent days with topiramate compared to placebo [54]. Currently, topiramate is not FDA-approved for alcoholdependence treatment. Adverse effects of topiramate include dose-dependent neurological reactions. Further studies are required to determine the optimal dosing.

Gabapentin, an antiepileptic medication that acts at calcium channels and stimulates GABA-B receptors, was first reported to reduce drinking when combined with naltrexone compared to naltrexone alone or placebo [55]. A 12-week RCT 
conducted in 150 recently abstinent alcohol-dependent outpatients showed superiority of gabapentin to placebo in reducing drinking [56]. High-dose gabapentin $(1,800 \mathrm{mg})$ reduced heavy drinking and craving and improved sleep more than low-dose gabapentin or placebo. Baclofen, a GABA-B receptor agonist that is used to treat spasticity, has shown efficacy and safety in a subset of alcohol-dependent patients with advanced liver cirrhosis [57].

\section{Serotonergic and Dopaminergic Medications}

Given the importance of dopamine and serotonin neurobiology in alcohol dependence, there is interest in medications that modify these neurotransmitters. In two separate 12-week RCTs of dopamine antagonists, olanzapine reduced alcohol craving and consumption [58], and quetiapine reduced heavy drinking [59]. However, a subsequent multisite RCT in heavy drinkers found quetiapine not effective in reducing drinking [60].

Buspirone is an anxiolytic with serotonin partial agonist effects and an antagonist at the dopamine- 2 receptor. A double-blind, placebo-controlled study in non-anxious alcoholics failed to show efficacy for buspirone in reducing drinking or craving [61].

Selective serotonin reuptake inhibitors (SSRIs), which augment serotonergic function, appear to reduce alcohol consumption in animal studies. In heavy drinking humans, SSRIs reduced alcohol consumption by 15-20 percent [62]. Further studies failed to replicate these modest results. A doubleblind, placebo-controlled study of fluoxetine found no difference in drinking in non-depressed patients [63]. However, studies have suggested that SSRIs may have efficacy in a subtype of alcoholic characterized by later age of drinking onset and less severe psychopathology [64].

Ondansetron, a serotonin-3 receptor antagonist used to treat nausea, was efficacious in alcohol-dependent subjects with early onset of alcoholism (i.e., prior to age 25) [65]. A more recent study demonstrated ondansetron's efficacy in patients with variants in genes encoding the serotonin transporter or serotonin-3 receptors [66].

\section{Medications to Treat Opioid Dependence}

The most widely used pharmacological treatments for opioiddependent individuals include maintenance treatments with full and partial opioid agonists as well as opioid antagonists. These medications are most effective when used in a structured treatment program, including monitored medication administration, random urine toxicological screening for compliance and intensive psychological, medical and vocational services. Agonist substitution maintains opioid dependence in a safe and controlled manner, reduces illicit opioid use and stabilizes mood, thereby decreasing the need for self- medication. Substitution treatments also provide incentives for patients to engage in other therapies.

\section{Methadone Maintenance}

Methadone is an oral, synthetic, mu-opioid agonist, with a long duration of action, minimal sedation or "high" and few side effects at therapeutic doses. Its efficacy has been established in the treatment of opioid-dependent patients [67]. Methadone is a widely utilized treatment for opioid dependence, with over 250,000 persons receiving daily treatment in the USA, and is highly regulated by government agencies. Methadone is administered daily, usually under observation, although long-time program participants are allowed "take-home" doses of methadone. Doses of methadone usually range from $20 \mathrm{mg}$ per day to over $100 \mathrm{mg}$ per day.

A meta-analysis comparing methadone maintenance to placebo or drug-free treatment found methadone to be significantly better than non-pharmacologic therapy for reducing heroin use and improving treatment retention [68]. Methadone treatment is associated with better physical health, less criminality, greater employment, reduced HIV transmission, and less opioid-related mortality and morbidity [69]. A longitudinal study found that the most effective methadone maintenance programs provided intensive psychosocial and medical services, flexibility in methadone dosing and higher doses of methadone, in excess of $80 \mathrm{mg}$ per day [70, 71].

\section{Buprenorphine}

Buprenorphine, an opioid partial agonist, having both agonist (predominating at lower doses) and antagonist (predominating at higher doses) properties, is effective in the maintenance treatment of opioid dependence $[72,73]$. Physicians trained in its use may treat up to 100 opioid-dependent patients; psychosocial treatment is a required element of the therapy. Randomized trials comparing buprenorphine to methadone maintenance in 164 subjects for 16 weeks and in 96 subjects for 6 months using a stepped-care approach showed similar reductions in illicit drug use and similar treatment retention [74, 75]. Advantages of buprenorphine compared to methadone include less intense withdrawal upon discontinuation, less abuse potential, as agonist effects diminish at higher doses, and less cardiotoxicity. Maintenance doses usually range from $4 \mathrm{mg}$ to $16 \mathrm{mg}$ daily. A preparation containing buprenorphine and naloxone was developed to discourage abuse by intravenous injection (naloxone precipitates withdrawal). Buprenorphine is now the most common medication used for opioid-dependence treatment and is available as sublingual tablets or strips and buprenorphine/naloxone tablets or strips $[69,72]$. 


\section{Naltrexone}

Naltrexone, an oral opioid antagonist, reduces illicit opioid use, particularly in highly motivated individuals with good social support [76]. Naltrexone blocks the intoxicating effects of opioids and craving, and it is unlikely to be diverted. The usual naltrexone dose is $50 \mathrm{mg}$ per day, although three times weekly dosing with 100, 100 and $150 \mathrm{mg}$ has also been shown to be effective [77]. Patients must be opioid free for a period of approximately 2 weeks before starting naltrexone treatment to avoid opioid withdrawal symptoms.

A sustained-release naltrexone preparation was developed to address poor medication adherence among opioiddependent individuals. Previously approved to treat alcohol dependence, it was approved in 2010 to treat opioid dependence as well. In a multicenter RCT of 250 opioid-dependent patients, once monthly injections of a sustained-release naltrexone preparation produced dose-dependent reductions in illicit drug use and improvements in treatment retention [78].

\section{Medications to Treat Nicotine Dependence}

Nicotine dependence is most successfully treated with combined pharmacologic and behavioral therapies [79-81]. According to clinical practice guidelines developed by the Department of Health and Human Services [82], all nicotinedependent patients should be offered some form of pharmacotherapy unless medical conditions contraindicate it. Three classes of pharmacotherapy have demonstrated efficacy for smoking cessation: nicotine replacement therapy, bupropion and varenicline [83].

\section{Nicotine Replacement [84]}

Nicotine replacement therapy (NRT) provides nicotine in a form free of the carcinogenic chemicals found in tobacco products. Four methods of nicotine administration have been approved: gum, transdermal patch, intranasal spray and orally inhaled "e-cigarettes." Although nicotine replacement has been used primarily for detoxification and relief of withdrawal during smoking cessation, some patients use nicotine replacement as maintenance therapy [85].

Nicotine gum consists of 2-4 mg nicotine within a resin matrix, with sweeteners and flavors. The gum is chewed slowly, releasing the nicotine, and then "parked" in contact with the buccal mucosa to promote absorption. Too rapid chewing releases excess nicotine and may cause nausea and other side effects. The gum is chewed for 20-30 min and then discarded. This method produces nicotine blood levels that rise and fall, partially mimicking smoking.

Nicotine transdermal patches, available both over the counter and by prescription, consist of nicotine (7, 14 and $21 \mathrm{mg}$ ) in a 24-h sustained-release adhesive patch. Patch nicotine blood levels are relatively constant throughout the application period. One patch is applied to the skin each $24 \mathrm{~h}$ and the previous patch discarded. Some wear the patches during daytime only and remove them while asleep. Side effects include irritation from the patch, nausea, insomnia and rapid pulse. Patients should not use tobacco products while using the patch, as toxic nicotine blood levels may occur. Nicotine nasal sprays and oral inhalers mimic the rapid nicotine delivery of cigarette smoke without its toxic elements. The inhaler has a plastic tip that is used like a cigarette, delivering a small dose of nicotine with each puff.

\section{Bupropion and Other Antidepressants}

The antidepressants desipramine, doxepin and bupropion, all of which block norepinephrine and/or dopamine uptake, are reportedly effective for smoking cessation. Sustained-released bupropion, marketed for this use as Zyban ${ }^{\circledR}$, is the only antidepressant that is FDA approved for smoking cessation. Bupropion reduces nicotine withdrawal signs and symptoms and may reduce the weight gain associated with quitting smoking [81]. A 7-week RCT of sustained-release bupropion in 615 smokers showed that the drug was effective for smoking cessation [81]. An open-label treatment with 784 nicotine-dependent subjects randomized to sustained-release bupropion or placebo for 45 weeks showed that sustainedrelease bupropion delayed smoking relapse [86].

\section{Varenicline}

Varenicline, a nicotinic receptor partial agonist, blocks the behavioral effects of nicotine during smoking and prevents withdrawal during abstinence. Several multicenter RCTs showed varenicline's tolerability and effectiveness in the treatment of tobacco dependence [87, 88]. A meta-analysis has also suggested that varenicline is more efficacious than bupropion [89]. In 2009, following reports of mood changes and suicidality in patients receiving varenicline, the FDA required that the drug's label include a "black box" warning. However, recent studies comparing varenicline with other smoking cessation treatments failed to show significant suicidal risk [90].

\section{Medications to Treat Cocaine Dependence}

Several pharmacological agents have been tested as adjuncts in the treatment of cocaine dependence, with the goal of reducing craving and relapse. Although some agents, including the antidepressant desipramine, have shown initial promise, follow-up studies with these agents have not consistently replicated these findings [91]. Currently, no medication is approved to treat cocaine dependence [69]. 
Several dopamine agonists, including bromocriptine, amantadine, mazindol and others, have also been tested in cocaine dependence, but have not been consistently effective. Some researchers have reported that methylphenidate may reduce cocaine relapse, particularly in patients who also have attention deficit hyperactivity disorder. The doses used are 15$60 \mathrm{mg}$ daily. Since methylphenidate is a controlled substance with abuse potential, careful selection of patients is necessary [92]. Recently, the indole alkaloid ibogaine was shown to decrease stimulant use in animals and is being tested in cocaine-dependent patients [93]. The opioid partial agonist buprenorphine has been shown to reduce cocaine use more than methadone maintenance in patients with combined opioid and cocaine dependence [94].

Disulfiram, used to treat alcohol dependence, may also have efficacy in cocaine treatment through an inhibitory effect on the brain enzyme, dopamine- $\beta$-hydroxylase. In a clinical trial in 121 cocaine-dependent patients, individuals randomized to receive treatment with disulfiram together with one of two types of behavioral therapy showed a significant reduction in cocaine use compared to the placebo group [95].

An RCT of the GABA B-agonist baclofen in 70 cocainedependent outpatients showed that it reduced cocaine use, particularly in heavy users [96]. A pilot trial with 40 cocaine-dependent subjects showed that topiramate-treated subjects were more likely to be abstinent from cocaine compared to placebo-treated subjects [97]. These findings were replicated in an RCT in 142 cocaine-dependent subjects [98]; however, another RCT with 170 cocaine-dependent subjects over 13 weeks failed to reproduce these results [99].

Another promising stimulant investigated for the treatment of cocaine dependence is modafinil $[69,100]$. Modafinil binds to norepinephrine and dopamine transporters, but may also affect oxexin-mediated arousal. A clinical trial in 62 cocaine-dependent subjects also receiving twice-weekly cognitive behavioral therapy found that modafinil-treated subjects significantly decreased cocaine use compared to those given placebo [101]. Modafinil appears to reduce the craving, anergia and anhedonia associated with cocaine withdrawal. A more recent RCT in 210 cocainedependent subjects failed to reproduce these results [102].

\section{Medications to Treat Gambling Dependence}

Multiple neurochemical targets have been investigated in the treatment of gambling dependence. Despite the central role of the dopaminergic system in the reward pathway, dopamine receptor antagonists are not efficacious in the treatment of gambling disorders. Two RCTs of olanzapine to treat pathological gambling in 21 subjects over 7 weeks and in 42 subjects over 12 weeks showed no reductions in gambling behaviors $[103,104]$. Tolcapone, an inhibitor of cathecol-Omethyltransferase (COMT), the enzyme responsible for dopamine degradation, was recently tested to treat gambling disorder. In an open-label, proof-of-concept study in 24 subjects with gambling addiction, tolcapone reduced symptoms most in a subset of the population with the val/val COMT genotype [105].

Gambling treatments using opioid receptor antagonists appear to result in the most positive outcomes, effects that may be mediated by dopaminergic modulation in the mesolimbic pathway. The beneficial effects are most pronounced in subjects with a family history of alcohol dependence [106]. An 11-week RCT of naltrexone at a dosage as high as $250 \mathrm{mg} /$ day in 45 subjects showed significantly greater improvements in all gambling symptom measures in the active treatment group [107]. These results were replicated in an 18-week RCT of 77 subjects, in which no differences in outcome were noted for dosages of 50,100 or $150 \mathrm{mg}$ /day [108]. Similarly, nalmefene was significantly superior to placebo in reducing the symptoms and severity of gambling behavior in two RCTs $[109,110]$.

Mood stabilizers have also been evaluated in the treatment of pathological gambling. Lithium was found to be superior to placebo in reducing craving and gambling behaviors in a 10week study of 40 pathological gamblers [111]. Topiramate was not a useful treatment in a 14-week study of 42 subjects [112].

Pallessen et al., in a meta-analysis of 16 RCTs of a variety of medications, found that pharmacological treatment of pathological gambling is consistently superior to placebo with an effect size of 0.78 (95\% CI 0.64-0.92), but that effect sizes were negatively related to the number of male subjects assessed in the study. They also found no significant outcome differences among the different classes of medications evaluated [113]. A more recent meta-analysis showed a small but significant benefit over placebo in the use of opioid antagonists, but not other classes of medications [114].

\section{Issues in Medications for Alcohol and Drug-dependence} Treatment

Medications may be best used as part of a comprehensive treatment program that addresses the psychological, social and spiritual needs of the patient. Several step-by-step treatment procedures have been developed to integrate psychosocial therapies with pharmacotherapies for alcohol and drug use disorders $[115,116]$. These procedures utilize patient education, feedback, emotional support and medication monitoring and, in the context of a brief intervention and motivational enhancement model, support medication adherence.

\section{Conclusion}

Considerable evidence supports the use of pharmacological treatment as an adjunct to traditional psychosocial therapies to 
enhance success in treating addictions. Effective FDAapproved pharmacotherapies currently exist for alcohol, opioid and nicotine dependence. In the future, new pharmacotherapies will be developed that are more efficacious, costeffective, matched to treatment based on patient characteristics, and useful outside of specialty settings (e.g., in primary care). Because pharmacotherapies will only be effective to the extent that clinicians and patients accept them, efforts are required to increase the awareness of their potential benefits in the treatment of addictive disorders.

\section{Compliance with Ethics Guidelines}

Conflict of Interest Elie Aoun has no conflicts of interest. Robert M. Swift received honoraria from D\&A Pharma. Swift received a grant from Farmaceutico CT San Remo. Swift will receive travel reimbursement from Lundbeck.

Human and Animal Rights and Informed Consent This article does not contain any studies with human or animal subjects performed by the author.

\section{References}

1. Koob GF, Volkow ND. Neurocircuitry of addiction. Neuropsychopharmacology. 2010;35(1):217-38.

2. McLellan AT, Lewis DC, O'Brien CP, Kleber HD. Drug dependence, a chronic medical illness: implications for treatment, insurance, and outcomes evaluation. JAMA. 2000;284(13):1689-95.

3. Probst CC, van Eimeren T. The functional anatomy of impulse control disorders. Curr Neurol Neurosci Rep. 2013;13(10):386.

4. Robinson TE, Berridge KC. The neural basis of drug craving: an incentive-sensitization theory ofaddiction. Brain Res Brain Res Rev. 1993;18(3):247-91.

5. Wise RA, Bozarth MA. A psychomotor stimulant theory of addiction. Psychol Rev. 1987;94(4):469-92.

6. Koob GF, Le Moal M. Drug addiction,dysregulation of reward, and allostasis. Neuropsychopharmacology. 2001;24(2):97-129.

7. Volkow ND, Fowler JS, Wang GJ, Swanson JM, Telang F. Dopamine in drug abuse and addiction: results of imaging studies and treatment implications. Arch Neurol. 2007;64(11):1575-9.

8. Wong DF, Kuwabara H, Schretlen DJ, Bonson KR, Zhou Y, Nandi A, et al. Increased occupancy of dopamine receptors in human striatum during cue-elicited cocaine craving. Neuropsychopharmacology. 2006;31(12):2716-27.

9. Littleton J. Neurochemical mechanisms underlying alcohol withdrawal. Alcohol Health Res World. 1998;22(1):13-24.

10. Blum K, Sheridan PJ, Wood RC, Braverman ER, Chen TJ, Cull JG, et al. The D2 dopamine receptor gene as a determinant of reward deficiency syndrome. J R Soc Med. 1996;89(7):396-400.

11. Koob GF. A role for brain stress systems in addiction. Neuron. 2008;59(1):11-34.

12. Elman I, Becerra L, Tschibelu E, Yamamoto R, George E, Borsook D. Yohimbine-induced amygdala activation in pathological gamblers: a pilot study. PLoS One. 2012;7(2):e31118.

13. Heilig M, Egli M, Crabbe JC, Becker HC. Acute withdrawal, protracted abstinence and negative affect in alcoholism: are they linked? Addict Biol. 2010;15(2):169-84.

14. Rohsenow DJ, Monti PM, Rubonis AV, Gulliver SB, Colby SM, Binkoff JA, et al. Cue exposure with coping skills training and communication skills training for alcohol dependence: 6- and 12month outcomes. Addiction. 2001;96(8):1161-74.

15. Graybiel AM. Habits, rituals, and the evaluative brain. Annu Rev Neurosci. 2008;31:359-87.

16. Mathur BN, Tanahira C, Tamamaki N, Lovinger DM. Voltage drives diverse endocannabinoid signals to mediate striatal microcircuit-specific plasticity. Nat Neurosci. 2013;16(9):1275-83.

17. Regier DA, Farmer ME, Rae DS, Locke BZ, Keith SJ, Judd LL, et al. Comorbidity of mental disorders with alcohol and other drug abuse. Results from the Epidemiologic Catchment Area (ECA) Study. JAMA. 1990;264(19):2511-8.

18. Chick J, Gough K, Falkowski W, Kershaw P, Hore B, Mehta B, et al. Disulfiram treatment of alcoholism. Br J Psychiatry. 1992;161: 84-9.

19. Wall TL. Genetic associations of alcohol and aldehyde dehydrogenase with alcohol dependence and their mechanisms of action. Ther Drug Monit. 2005;27(6):700-3.

20. Thomasson HR, Edenberg HJ, Crabb DW, Mai XL, Jerome RE, Li TK, et al. Alcohol and aldehyde dehydrogenase genotypes and alcoholism in Chinese men. Am J Hum Genet. 1991;48(4): 677-81.

21. Fuller RK, Branchey L, Brightwell DR, Derman RM, Emrick CD, Iber FL, et al. Disulfiram treatment of alcoholism. A veterans administration cooperative study. JAMA. 1986;256(11):1449-55.

22. Carroll KM, Nich C, Ball SA, McCance E, Rounsavile BJ. Treatment of cocaine and alcohol dependence with psychotherapy and disulfiram. Addiction. 1998;93(5):713-27.

23. Suh JJ, Pettinati HM, Kampman KM, O'Brien CP. The status of disulfiram: a half of a century later. J Clin Psychopharmacol. 2006;26(3):290-302.

24. O'Farrell TJ, Allen JP, Litten RZ. Disulfiram (antabuse) contracts in treatment of alcoholism. NIDA Res Monogr. 1995;150:65-91.

25. Volpicelli JR, Alterman AI, Hayashida M, O'Brien CP. Naltrexone in the treatment of alcohol dependence. Arch Gen Psychiatry. 1992;49(11):876-80.

26. O'Malley SS, Jaffe AJ, Chang G, Schottenfeld RS, Meyer RE, Rounsaville B. Naltrexone and coping skills therapy for alcohol dependence. Arch Gen Psychiatry. 1992;49(11):881-7.

27. Srisurapanont M, Jarusuraisin N. Naltrexone for the treatment of alcoholism: a meta-analysis of randomized controlled trials. Int $\mathrm{J}$ Neuropsychopharmacol. 2005;8(2):267-80.

28. Bouza C, Angeles M, Muñoz A, Amate JM. Efficacy and safety of naltrexone and acamprosate in the treatment of alcohol dependence: a systematic review. Addiction. 2004;99(7):811-28.

29. Rösner S, Hackl-Herrwerth A, Leucht S, Vecchi S, Srisurapanont M, Soyka M. Opioid antagonists for alcohol dependence. Cochrane Database Syst Rev. 2010;12, CD001867.

30. Rösner S, Leucht S, Lehert P, Soyka M. Acamprosate supports abstinence, naltrexone prevents excessive drinking: evidence from a meta-analysis with unreported outcomes. J Psychopharmacol. 2008;22(1):11-23.

31. Oslin DW, Berrettini W, Kranzler HR, Pettinati H, Gelernter J, Volpicelli JR, et al. A functional polymorphism of the mu-opioid receptor gene is associated with naltrexone response in alcoholdependent patients. Neuropsychopharmacology. 2003;28(8): 1546-52.

32. Anton RF, Oroszi G, O'Malley S, Couper D, Swift R, Pettinati H, et al. An evaluation of mu-opioid receptor (OPRM1) as a predictor of naltrexone response in the treatment of alcohol dependence: results from the Combined Pharmacotherapies and Behavioral Interventions for Alcohol Dependence (COMBINE) study. Arch Gen Psychiatry. 2008;65(2):135-44.

33. Croop RS, Faulkner EB, Labriola DF. The safety profile of naltrexone in the treatment of alcoholism. Results from a multicenter usage study. The Naltrexone Usage Study Group. Arch Gen Psychiatry. 1997;54(12):1130-5. 
34. SAMSHA. Treatment Improvement Protocol; Naltrexone in the Treatment of Alcohol Dependence. Treatment Improvement Protocols (TIPS). Washington, DC: DHHS, 1997

35. Garbutt JC, Kranzler HR, O'Malley SS, Gastfriend DR, Pettinati HM, Silverman BL, et al. Efficacy and tolerability of long-acting injectable naltrexone for alcohol dependence: a randomized controlled trial. JAMA. 2005;293(13):1617-25.

36. Mason BJ, Ritvo EC, Morgan RO, Salvato FR, Goldberg G, Welch $\mathrm{B}$, et al. A double-blind, placebo-controlled pilot study to evaluate the efficacy and safety of oral nalmefene $\mathrm{HCl}$ for alcohol dependence. Alcohol Clin Exp Res. 1994;18(5):1162-7.

37. Mason BJ, Salvato FR, Williams LD, Ritvo EC, Cutler RB. A double-blind, placebo-controlled study of oral nalmefene for alcohol dependence. Arch Gen Psychiatry. 1999;56(8):719-24.

38. Anton RF, Pettinati H, Zweben A, Kranzler HR, Johnson B, Bohn $\mathrm{MJ}$, et al. A multi-site dose ranging study of nalmefene in the treatment of alcohol dependence. J Clin Psychopharmacol. 2004;24(4):421-8.

39. Mann K, Bladström A, Torup L, Gual A, van den Brink W. Extending the treatment options in alcohol dependence: a randomized controlled study of as-needed nalmefene. Biol Psychiatry. 2013;73(8):706-13.

40. Gual A, He Y, Torup L, van den Brink W, Mann K. ESENSE 2 Study Group. A randomised, double-blind, placebo-controlled, efficacy study of nalmefene, as-needed use, in patients withalcohol dependence. Eur Neuropsychopharmacol. 2013;23(11):1432-42.

41. Littleton J. Acamprosate in alcohol dependence: how does it work? Addiction. 1995;90(9):1179-88.

42. Swift R. Emerging approaches to managing alcohol dependence. Am J Health Syst Pharm. 2007;64(5 Suppl 3):S12-22.

43. Paille FM, Guelfi JD, Perkins AC, Royer RJ, Steru L, Parot P. Double-blind randomized multicentre trial of acamprosate in maintaining abstinence from alcohol. Alcohol Alcohol. 1995;30(2): 239-47.

44. Pelc I, Verbanck P, Le Bon O, Gavrilovic M, Lion K, Lehert P. Efficacy and safety of acamprosate in the treatment of detoxified alcohol-dependent patients. A 90-day placebo-controlled dosefinding study. Br J Psychiatry. 1997;171:73-7.

45. Sass H, Soyka M, Mann K, Zieglgänsberger W. Relapse prevention by acamprosate. Results from a placebo-controlled study on alcohol dependence. Arch Gen Psychiatry. 1996;53(8):673-80.

46. Mann K, Lehert P, Morgan MY. The efficacy of acamprosate in the maintenance of abstinence in alcohol-dependent individuals: results of a meta-analysis. Alcohol Clin Exp Res. 2004;28(1): 51-63.

47. Mason BJ, Goodman AM, Chabac S, Lehert P. Effect of oral acamprosate on abstinence in patients with alcohol dependence in a double-blind, placebo-controlled trial: the role of patient motivation. J Psychiatr Res. 2006;40(5):383-93.

48. Anton RF, O'Malley SS, Ciraulo DA, Cisler RA, Couper D, Donovan DM, et al. COMBINE Study Research Group. Combined pharmacotherapies and behavioral interventions for alcohol dependence: the COMBINE study: a randomized controlled trial. JAMA. 2006;295(17):2003-17.

49. Mann K, Lemenager T, Hoffmann S, Reinhard I, Hermann D, Batra A, et al. PREDICT Study Team. Results of a double-blind, placebocontrolled pharmacotherapy trial in alcoholism conducted in Germany and comparison with the US COMBINE study. Addict Biol. 2013;18(6):937-46.

50. Caputo F. Gamma-hydroxybutyrate (GHB) for the treatment of alcohol dependence: a call for further understanding. Alcohol Alcohol. 2011;46(1):3.

51. Mueller TI, Stout RL, Rudden S, Brown RA, Gordon A, Solomon DA, et al. A double-blind, placebo-controlled pilot study of carbamazepine for the treatment of alcohol dependence. Alcohol Clin Exp Res. 1997;21(1):86-92.
52. Johnson BA, Ait-Daoud N, Bowden CL, DiClemente CC, Roache JD, Lawson K, et al. Oral topiramate for treatment of alcohol dependence: a randomised controlled trial. Lancet. 2003;361(9370): 1677-85.

53. Johnson BA, Rosenthal N, Capece JA, Wiegand F, Mao L, Beyers K, et al. Topiramate for Alcoholism Study Group. Topiramate for treating alcohol dependence: a randomized controlled trial. JAMA. 2007;298(14):1641-51.

54. Kranzler HR, Covault J, Feinn R, Armeli S, Tennen H, Arias AJ, et al. Topiramate treatment for heavy drinkers: moderation by a GRIK1 polymorphism. Am J Psychiatry. 2014;171(4): 445-52.

55. Anton RF, Myrick H, Wright TM, Latham PK, Baros AM, Waid LR, et al. Gabapentin combined with naltrexone for the treatment of alcohol dependence. Am J Psychiatry. 2011;168(7):709-17.

56. Mason BJ, Quello S, Goodell V, Shadan F, Kyle M, Begovic A. Gabapentin treatment for alcohol dependence: a randomized clinical trial. JAMA Intern Med. Published online November 4, 2013.

57. Brennan JL, Leung JG, Gagliardi JP, Rivelli SK, Muzyk AJ. Clinical effectiveness of baclofen for the treatment of alcohol dependence: a review. Clin Pharmacol. 2013;5:99-107.

58. Hutchison KE, Ray L, Sandman E, Rutter MC, Peters A, Davidson $\mathrm{D}$, et al. The effect of olanzapine on craving and alcohol consumption. Neuropsychopharmacology. 2006;31(6):1310-7.

59. Kampman KM, Pettinati HM, Lynch KG, Whittingham T, Macfadden W, Dackis C, et al. A double-blind, placebo-controlled pilot trial of quetiapine for the treatment of type A and type B alcoholism. J Clin Psychopharmacol. 2007;27(4):344-51.

60. Litten RZ, Fertig JB, Falk DE, Ryan ML, Mattson ME, Collins JF, et al. NCIG 001 Study Group. A double-blind, placebo-controlled trial to assess the efficacy of quetiapine fumarate XR in very heavydrinking alcohol-dependent patients. Alcohol Clin Exp Res. 2012;36(3):406-16.

61. Malec E, Malec T, Gagné MA, Dongier M. Buspirone in the treatment of alcohol dependence: a placebo-controlled trial. Alcohol Clin Exp Res. 1996;20(2):307-12.

62. Naranjo CA, Bremner KE. Clinical pharmacology of serotoninaltering medications for decreasing alcohol consumption. Alcohol Alcohol Suppl. 1993;2:221-9.

63. Kranzler HR, Burleson JA, Korner P, Del Boca FK, Bohn MJ, Brown J, et al. Placebo-controlled trial of fluoxetine as an adjunct to relapse prevention in alcoholics. Am J Psychiatry. 1995;152(3): 391-7.

64. Kranzler HR, Armeli S, Tennen H, Covault J, Feinn R, Arias AJ, et al. A double-blind, randomized trial of sertraline for alcohol dependence: moderation by age of onset [corrected] and 5hydroxytryptamine transporter-linked promoter region genotype. J Clin Psychopharmacol. 2011;31(1):22-30.

65. Johnson BA, Roache JD, Javors MA, DiClemente CC, Cloninger $\mathrm{CR}$, Prihoda TJ, et al. Ondansetron for reduction of drinking among biologically predisposed alcoholic patients: a randomized controlled trial. JAMA. 2000;284(8):963-71.

66. Johnson BA, Seneviratne C, Wang XQ, Ait-Daoud N, Li MD. Determination of genotype combinations that can predict the outcome of the treatment of alcohol dependence using the 5-HT(3) antagonist ondansetron. Am J Psychiatry. 2013;170(9):1020-31.

67. Senay EC. Methadone maintenance treatment. Int J Addict. 1985;20(6-7):803-21.

68. Mattick RP, Breen C, Kimber J, Davoli M. Methadone maintenance therapy versus no opioid replacement therapy for opioid dependence. Cochrane Database Syst Rev. 2003;2, CD002209.

69. Vocci FJ, Acri J, Elkashef A. Medication development for addictive disorders: the state of the science. Am J Psychiatry. 2005;162(8): $1432-40$.

70. D'Aunno T, Vaughn TE. Variations in methadone treatment practices. Results from a national study. JAMA. 1992;267(2):253-8. 
71. D'Aunno T, Pollack HA. Changes in methadone treatment practices: results from a national panel study, 1988-2000. JAMA. 2002;288(7):850-6.

72. Ling W, Rawson RA, Compton MA. Substitution pharmacotherapies for opioid addiction: from methadone to LAAM and buprenorphine. J Psychoactive Drugs. 1994;26(2):119-28.

73. Compton PA, Wesson DR, Charuvastra VC, Ling W. Buprenorphine as a pharmacotherapy for opiate addiction. Am J Addict. 1996;5:220-30.

74. Kakko J, Grönbladh L, Svanborg KD, von Wachenfeldt J, Rück C, Rawlings B, et al. A stepped care strategy using buprenorphine and methadone versus conventional methadone maintenance in heroin dependence: a randomized controlled trial. Am J Psychiatry. 2007;164(5):797-803.

75. Strain EC, Stitzer ML, Liebson IA, Bigelow GE. Comparison of buprenorphine and methadone in the treatment of opioid dependence. Am J Psychiatry. 1994;151(7):1025-30.

76. Ginzburg HM. Naltrexone: Its clinical utility. NIDA Treatment Research Report. Vol. (ADM)86-1358. Rockville, MD: DHHS Pub, 1986.

77. Tetrault JM, Fiellin DA. Current and potential pharmacological treatment options for maintenance therapy in opioid-dependent individuals. Drugs. 2012;72(2):217-28.

78. Krupitsky E, Nunes EV, Ling W, Illeperuma A, Gastfriend DR, Silverman BL. Injectable extended-release naltrexone for opioid dependence: a double-blind, placebo-controlled, multicentre randomised trial. Lancet. 2011;377(9776):1506-13.

79. Hughes JR, Goldstein MG, Hurt RD, Shiffman S. Recent advances in the pharmacotherapy of smoking. JAMA. 1999;281(1):72-6.

80. Treating Tobacco Use and Dependence: 2008 Update Tobacco Use and Dependence Guideline Panel. Rockville (MD):US Department of Health and Human Services; May 2008.

81. Hurt RD, Sachs DP, Glover ED, Offord KP, Johnston JA, Dale LC, et al. A comparison of sustained-release bupropion and placebo for smoking cessation. N Engl J Med. 1997;337(17): 1195-202.

82. United States Department of Health and Human Services. (2000). Treating Tobacco Use and Dependence: Clinical Practice Guideline. Public Health Service: USDHHS, Washington, DC. Le Foll, B. and George, T.P. (2007) Treatment of tobacco dependence: integrating recent progress into practice. CMAJ 177, 1373-1380

83. Stead LF, Perera R, Bullen C, Mant D, Hartmann-Boyce J, Cahill K, et al. Nicotine replacement therapy for smoking cessation. Cochrane Database Syst Rev. 2012;14(11):CD000146.

84. Fiore MC, Baker TB. Clinical practice. Treating smokers in the health care setting. N Engl J Med. 2011;365(13):1222-31.

85. Jorenby DE, Leischow SJ, Nides MA, Rennard SI, Johnston JA, Hughes AR, et al. A controlled trial of sustained-release bupropion, a nicotine patch, or both for smoking cessation. N Engl J Med. 1999;340(9):685-91.

86. Hays JT, Hurt RD, Rigotti NA, Niaura R, Gonzales D, Durcan MJ, et al. Sustained-release bupropion for pharmacologic relapse prevention after smoking cessation. A randomized, controlled trial. Ann Intern Med. 2001;135(6):423-33.

87. Nides M, Oncken C, Gonzales D, Rennard S, Watsky EJ, Anziano $\mathrm{R}$, et al. Smoking cessation with varenicline, a selective alpha4beta2 nicotinic receptor partial agonist: results from a 7-week, randomized, placebo- and bupropion-controlled trial with 1-year follow-up. Arch Intern Med. 2006;166(15):1561-8.

88. Oncken C, Gonzales D, Nides M, Rennard S, Watsky E, Billing CB, et al. Efficacy and safety of the novel selective nicotinic acetylcholine receptor partial agonist, varenicline, for smoking cessation. Arch Intern Med. 2006;166(15):1571-7.

89. Eisenberg MJ, Filion KB, Yavin D, Bélisle P, Mottillo S, Joseph L, et al. Pharmacotherapies for smoking cessation: a meta-analysis of randomized controlled trials. CMAJ. 2008;179(2):135-44.
90. Kuehn BM. New reports examine psychiatric risks of varenicline for smoking cessation. JAMA. 2012;307(2):129-30.

91. Levin FR, Lehman AF. Meta-analysis of desipramine as an adjunct in the treatment of cocaine addiction. J Clin Psychopharmacol. 1991;11(6):374-8.

92. Levin FR, Evans SM, Brooks DJ, Garawi F. Treatment of cocaine dependent treatment seekers with adult ADHD: double-blind comparison of methylphenidate and placebo. Drug Alcohol Depend. 2007;87(1):20-9.

93. Sershen H, Hashim A, Lajtha A. Ibogaine and cocaine abuse: pharmacological interactions at dopamine and serotonin receptors. Brain Res Bull. 1997;42(3):161-8.

94. Kosten TR, Kleber HD, Morgan C. Treatment of cocaine abuse with buprenorphine. Biol Psychiatry. 1989;26(6):637-9.

95. Carroll KM, Nich C, Ball SA, McCance E, Frankforter TL, Rounsaville BJ. One-year follow-up of disulfiram and psychotherapy for cocaine-alcohol users: sustained effects of treatment. Addiction. 2000;95(9):1335-49.

96. Shoptaw S, Yang X, Rotheram-Fuller EJ, Hsieh YC, Kintaudi PC, Charuvastra VC, et al. Randomized placebo-controlled trial of baclofen for cocaine dependence: preliminary effects for individuals with chronic patterns of cocaine use. J Clin Psychiatry. 2003;64(12): 1440-8.

97. Kampman KM, Pettinati H, Lynch KG, Dackis C, Sparkman T, Weigley $\mathrm{C}$, et al. A pilot trial of topiramate for the treatment of cocaine dependence. Drug Alcohol Depend. 2004;75(3):233-40.

98. Johnson BA, Ait-Daoud N, Wang XQ, Penberthy JK, Javors MA, Seneviratne $\mathrm{C}$, et al. Topiramate for the treatment of cocaine addiction: a randomized clinical trial. JAMA Psychiatry. 2013;70(12): 1338-46.

99. Kampman KM, Pettinati HM, Lynch KG, Spratt K, Wierzbicki MR, O'Brien CP. A double-blind, placebo-controlled trial of topiramate for the treatment of comorbid cocaine and alcohol dependence. Drug Alcohol Depend. 2013;133(1):94-9.

100. Dackis CA, Lynch KG, Yu E, Samaha FF, Kampman KM, Cornish JW, et al. Modafinil and cocaine: a double-blind, placebocontrolled drug interaction study. Drug Alcohol Depend. 2003;70(1):29-37.

101. Dackis CA, Kampman KM, Lynch KG, Pettinati HM, O'Brien CP. A double-blind, placebo-controlled trial of modafinil for cocaine dependence. Neuropsychopharmacology. 2005;30(1):205-11.

102. Dackis CA, Kampman KM, Lynch KG, Plebani JG, Pettinati HM, Sparkman T, et al. A double-blind, placebo-controlled trial of modafinil for cocaine dependence. J Subst Abuse Treat. 2012;43(3):303-12.

103. McElroy SL, Nelson EB, Welge JA, Kaehler L, Keck Jr PE. Olanzapine in the treatment of pathological gambling: a negative randomized placebo-controlled trial. J Clin Psychiatry. 2008;69(3): 433-40.

104. Fong T, Kalechstein A, Bernhard B, Rosenthal R, Rugle L. A double-blind, placebo-controlled trial of olanzapine for the treatment of video poker pathological gamblers. Pharmacol Biochem Behav. 2008;89(3):298-303.

105. Grant JE, Odlaug BL, Chamberlain SR, Hampshire A, Schreiber LR, Kim SW. A proof of concept study of tolcapone for pathological gambling: relationships with COMT genotype and brain activation. Eur Neuropsychopharmacol. 2013;23(11):1587-96.

106. Grant JE. Opioid antagonists in the treamtent of pathological gambling and kleptomania. Opiate receptors and antagonists. New York: Humana; 2009.

107. Kim SW, Grant JE, Adson DE, Shin YC. Double-blind naltrexone and placebo comparison study in the treatment of pathological gambling. Biol Psychiatry. 2001;49(11):914-21.

108. Grant JE, Kim SW, Hartman BK. A double-blind, placebo-controlled study of the opiate antagonist naltrexone in the treatment of pathological gambling urges. J Clin Psychiatry. 2008;69(5):783-9. 
109. Grant JE, Potenza MN, Hollander E, Cunningham-Williams R, Nurminen T, Smits G, et al. Multicenter investigation of the opioid antagonist nalmefene in the treatment of pathological gambling. Am J Psychiatry. 2006;163(2):303-12.

110. Grant JE, Odlaug BL, Potenza MN, Hollander E, Kim SW. Nalmefene in the treatment of pathological gambling: multicentre, double-blind, placebo-controlled study. Br J Psychiatry. 2010;197(4):330-1.

111. Hollander E, Pallanti S, Allen A, Sood E, Baldini RN. Does sustained-release lithium reduce impulsive gambling and affective instability versus placebo in pathological gamblers with bipolar spectrum disorders? Am J Psychiatry. 2005;162(1): $137-45$.

112. Berlin HA, Braun A, Simeon D, Koran LM, Potenza MN, McElroy SL, et al. A double-blind, placebo-controlled trial of topiramate for pathological gambling. World J Biol Psychiatry. 2013;14(2):121-8.

113. Pallesen S, Molde H, Arnestad HM, Laberg JC, Skutle A, Iversen E, et al. Outcome of pharmacological treatments of pathological gambling: a review and meta-analysis. J Clin Psychopharmacol. 2007;27(4):357-64.

114. Bartley CA, Bloch MH. Meta-analysis: pharmacological treatment of pathological gambling. Expert Rev Neurother. 2013;13(8):887-94.

115. Pettinati HM, Volpicelli JR, Pierce Jr JD, O'Brien CP. Improving naltrexone response: an intervention for medical practitioners to enhance medication compliance in alcohol dependent patients. $\mathrm{J}$ Addict Dis. 2000;19(1):71-83.

116. O'Malley SS, Carroll KM. Psychotherapeutic considerations in pharmacological trials. Alcohol Clin Exp Res. 1996;20(7 Suppl): $17 \mathrm{~A}-22 \mathrm{~A}$. 